\title{
Operating Conditions of Lead-Acid Batteries in the Optimization of Hybrid Energy Systems and Microgrids
}

\author{
Juan M. Lujano-Rojas ${ }^{\text {a,b }}$, Rodolfo Dufo-López ${ }^{\mathrm{c}}$, José L. Atencio-Guerra ${ }^{\mathrm{d}}$, \\ Eduardo M. G. Rodrigues ${ }^{a}$, José L. Bernal-Agustín ${ }^{c}$, and João P. S. Catalão $o^{\text {a,b,e }}$ \\ ${ }^{a}$ C-MAST, University of Beira Interior, R. Fonte do Lameiro, 6201-001 Covilhã, Portugal \\ ${ }^{b}$ INESC-ID, Instituto Superior Técnico, University of Lisbon, Av. Rovisco Pais, 1, 1049-001 Lisbon, Portugal \\ ${ }^{c}$ Department of Electrical Engineering, Universidad de Zaragoza, Calle María de Luna 3, 50018 Zaragoza, Spain \\ ${ }^{d}$ Technological University of Panama, Campus Metropolitano Víctor Levi Sasso, 0819-07289 El Dorado, Panama City, Panama \\ ${ }^{e}$ INESC TEC and Faculty of Engineering of the University of Porto, R. Dr. Roberto Frias, 4200-465 Porto, Portugal
}

\begin{abstract}
The promotion and deployment of storage technologies in autonomous and grid-connected systems plays a relevant part in the massive integration of renewable power sources required for the worldwide development of a sustainable society. In this regard, analyzing the behavior of electrochemical storage devices such as lead-acid batteries installed on hybrid energy systems and microgrids in terms of their lifetime and economic profitability is an important research topic. Since renewable generation is characterized by its random nature, lead-acid batteries typically work under stress conditions, which directly influence their lifetime in a negative way by increasing the net present cost. Due to the fast growing of renewable sources as a consequence of governmental policies and incentives, the number of manufacturers to be considered worldwide is becoming really high, so that optimization techniques such as genetic algorithms (GAs) are frequently used in order to consider the performance of a high number of manufacturers of wind turbines, photovoltaic panels and lead-acid batteries subject to the environmental conditions of the location under analysis to determine a cost-effective design. In this paper, GA method combined with weighted Ah ageing model is improved by including expert experiences by means of stress factors and the categorization of operating conditions, as a new contribution to earlier studies. The effectiveness of the proposed method is illustrated by analyzing a hybrid energy system to be installed in Zaragoza, Spain, resulting in a near-optimal design in a reduced computational time compared to the enumerative optimization method.
\end{abstract}

\section{List of symbols}

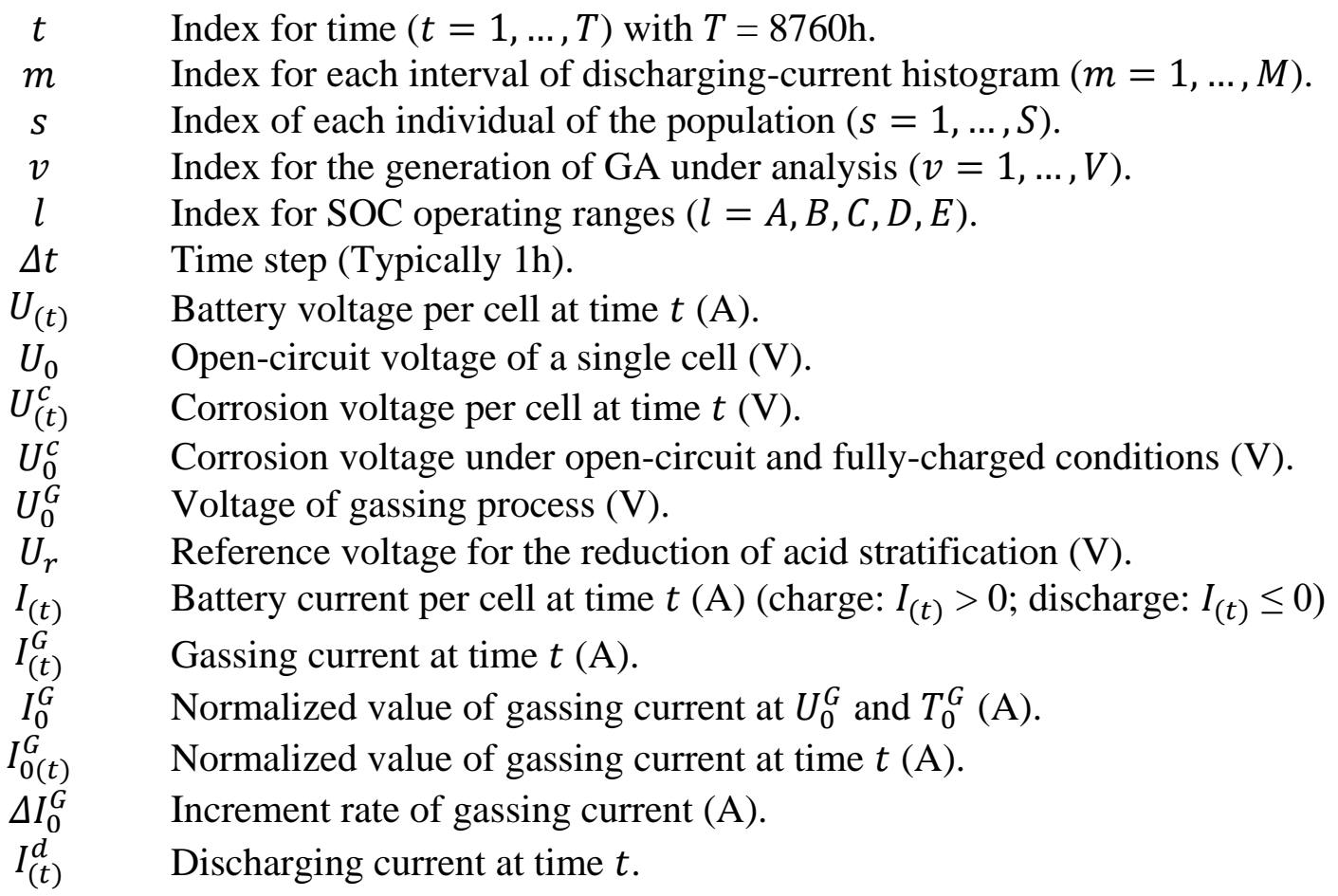




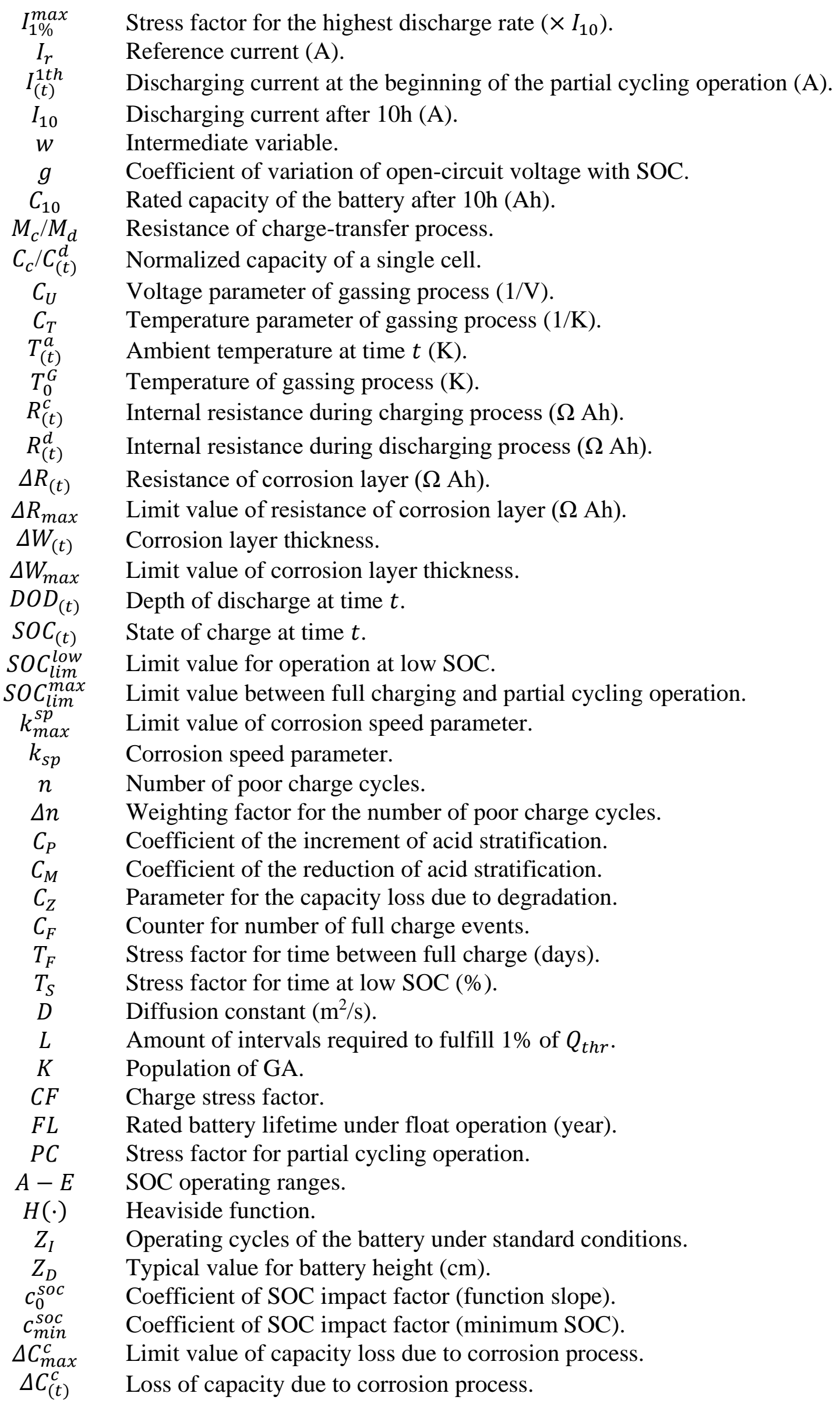


$\Delta C_{(t)}^{d} \quad$ Capacity loss due to degradation process.

$\Delta C_{\max }^{d} \quad$ Limit value of capacity loss due to degradation process.

$\Delta t_{(t)}^{\text {Soc }} \quad$ Time since the last full charge (h).

$\Delta f_{(t)}^{+} \quad$ Factor for the increment of acid stratification.

$\Delta f_{(t)}^{-} \quad$ Factor for the reduction of acid stratification.

$\Delta f_{G(t)}^{-} \quad$ Factor for the reduction of acid stratification due to gassing.

$\Delta f_{D(t)}^{-} \quad$ Factor for the reduction of acid stratification due to reduction.

$f_{(t)}^{s o c} \quad$ SOC impact factor.

$f_{(t)}^{I} \quad$ Current factor.

$f_{(t)}^{S T} \quad$ Factor for degree of acid stratification.

$f_{(t)}^{A} \quad$ Factor for total impact of acid stratification.

$Q_{t h r} \quad$ Normalized total Ah discharged per year $\left(\times C_{10}\right)$

$l_{(m)} \quad$ Interval $m$ of discharging-current histogram.

$f_{(m)} \quad$ Frequency of interval $m$ of discharging-current histogram.

$P_{(l)} \quad$ Partial cycling factor of range $l$.

$P_{(l)}^{\min } \quad$ Inferior limit of range $l$.

$P_{(l)}^{\max } \quad$ Superior limit of range $l$.

$F_{f(s)} \quad$ Value of fitness function for individual $s$.

$\vec{k}_{(s)} \quad$ Individual $s$ on the population.

$k_{(s)}^{1}-k_{(s)}^{4} \quad$ Chromosomes of individual $s$ of GA.

$k_{\min }^{1}-k_{\min }^{4} \quad$ Inferior limit for each chromosome.

$k_{\max }^{1}-k_{\max }^{4}$ Superior limit for each chromosome.

\section{Introduction}

Within energy system categories, Hybrid Energy Systems (HESs) and Microgrids (MGs) have gained attention due to their high integration of renewable resources, which, from an environmental viewpoint, is crucial for the development of a sustainable society. HESs typically operate in isolated regions with abundant natural resources [1], while MGs are provided with modern capabilities to integrate Battery Storage Systems (BSSs), distributed generation, and demand response programs, which increase the efficiency of the system, allowing for the active participation of the consumers [2]. In a general sense, these systems are mainly powered by renewable sources such as wind and solar energies, a conventional generating unit that operates during a short period of time or is dispatched producing a reduced amount of energy. A BSS is typically based on lead-acid technology [3] that provides flexibility to the system by storing the excess energy to be consumed later during those periods of low renewable energy [4]. On the one hand, BSS is the weakest element of the system, as its lifetime is difficult to understand and predict. On the other hand, the variability of renewable resources and the operating philosophy imposes stress conditions on the storing system, reducing its lifetime and increasing its Net Present Cost (NPC).

This problem has been widely studied for a long time, resulting in quantitative and qualitative approaches. Quantitative approaches could be classified in three different categories: physico-chemical ageing models, weighted Ah ageing models, and event-oriented ageing models. Physico-chemical ageing models are based on detailed knowledge of the relationship between the state variables and their corresponding effects on the ageing mechanisms, specifically, the degradation of the active mass and 
the loss of grid conductivity as a consequence of the corrosion process. This relationship is based on the mathematical equations of chemical reactions; hence, the operating conditions can be carefully described in terms of current density, gassing current, oxygen-reduction current, corrosion current, potential, State of Charge (SOC), and microstructure of active material, and the gas pressure for determined locations inside the battery. These models require information obtained from experimental tests; they offer high-precision results that require powerful computational resources. Weighted Ah ageing models were developed under the assumption that a constant amount of $A h$ is cycled before the battery reaches the end of its lifetime. This value can be estimated from information typically provided by the manufacturer and measured under standard conditions. As the operating and standard conditions are different, $A h$ cycled through the battery is weighted according to the operational conditions; so that, the limit value is rapidly reached, depending on how different the expected operating conditions are compared to the standard ones. In this way the reduction of the battery lifetime is represented. These models require the opinions of experts and information obtained from experimental tests. Due to their moderate level of complexity, these models offer simulation results of moderate precision, which are useful for optimal control and design. Similarly, in event-oriented ageing models, the severity of the reduction of battery lifetime as a consequence of a determined operating condition is assigned using Wöhler curves. The main events that are used frequently include float operation, cyclic operation, and cycling at partial SOC. These models are based on expert experiences, and so they offer a quite limited level of precision due to their low complexity level [5]. Regarding qualitative approaches, the most representative method consists of describing the relationship between the stress factors (e.g. long time at low SOC, $A h$-throughput, charge factor, time between full charge and temperature) and the corrosion of the positive grid, hard and irreversible sulphation, the loss of material, water loss or drying out, active mass degradation, and electrolyte stratification [6]. This information could be useful for getting a general idea of the operating conditions of BSS.

Manufacturers of wind turbines and Photovoltaic (PV) panels have grown significantly worldwide due to the importance of renewable energies. In order to obtain a near-optimal solution in a reasonable computational time, optimization techniques are frequently employed [7]. There are many computational tools for the analysis of HESs and MGs. Some representative examples of quantitative methods implemented using these tools are Hybrid Optimization Model for Electric Renewables (HOMER), improved Hybrid Optimization by Genetic Algorithm (iHOGA), and Hybrid2. HOMER is a simulation and optimization model developed by National Renewable Energy Laboratory (NREL) that is able to analyze systems composed of diesel generators, solar-PV generators, wind turbines, BSSs, and hydrogen fuel cells, among other components [8]. Initially, the enumerative optimization method was used by this software to determine the most profitable design; however, in its most recent release, the optimization technique was updated in order to enhance the computational efficiency of the program [9]. iHOGA was developed by the University of Zaragoza for the simulation and optimization of HESs with PV and wind generation, hydro turbines, BSSs, diesel generators, and fuel cells. It is able to perform mono- and multiobjective optimization by means of a Genetic Algorithm (GA) that includes control strategies. It also performs probabilistic optimization [10]. Hybrid2 is a simulation program jointly developed by NREL and Renewable Energy Research Laboratory (RERL) of the University of Massachusetts, and it is able to carry out accurate yearly simulations and economic analyses of HESs from both deterministic and probabilistic viewpoints [11]. 
Renewable Energy Systems Design Assistant for Storage (RESDAS) is an example of a qualitative approach implemented using a computational tool able to provide operational information from an installed or previously designed HES using the corresponding stress factors as input data. Depending on the amount of data available, general purpose suggestions are given to the HES designer [12].

With regard to battery lifetime estimation, the method used by HOMER only considers the amount of $A h$ cycled through the battery without taking into account the rest of the aforementioned stress factors, which could underestimate the NPC. Moreover, iHOGA uses the weighted Ah ageing model, requiring the extensive simulation of the battery lifetime on an hourly basis, which is a time-consuming task. However, this software takes advantage of GA characteristics in order to enhance the whole optimization process, offering good results in a short computational time. Hybrid 2 employs a modified method based on the cycle counting technique initially derived from the analysis of material fatigue damage and adapted for battery lifetime estimation using a Depth of Discharge (DOD) time series to define the battery operating cycles (Rain Flow counting algorithm). RESDAS provides very useful information about battery health and operational conditions. Nevertheless, it is not able to determine the impact of battery health on the NPC required to perform the economic analysis. Among quantitative approaches, the weighted Ah ageing model is considered to be a moderately accurate method that is flexible enough to be incorporated into the optimization of HESs. However, it simulates the HES on an hourly basis throughout the battery's entire lifetime, which could considerably increase the computational burden. As qualitative approaches are not suitable for economic analysis due to their intrinsically limited ability to estimate a numerical value for the battery's lifetime, it could be combined with an HES simulator to calculate the data required to estimate the stress levels and provide suggestions for the designer. This idea was previously proposed by the European Union Benchmarking Project, which used Hybrid2 as the main simulator [13]. Nonetheless, to the best of our knowledge, no method to integrate the quantitative and qualitative methods effectively with an optimization technique has been developed or made publically available.

In order to enhance the optimization procedure in terms of efficiency and reliability, in this paper, quantitative and qualitative approaches have been combined in a GA-based design method as a new contribution to earlier studies. For each individual of GA (a possible HES configuration), the previously described stress factors are estimated. If a determined configuration presents high risk of battery-lifetime reduction, this option is automatically rejected and assigned an artificially high value of NPC (low fitness to the corresponding individual). However, those configurations with low risk of battery-lifetime reduction are analyzed using the weighted Ah ageing model to estimate a reasonable value for the battery lifetime and the NPC. In this way, during the analysis of a specific generation of GA, not all individuals are evaluated, resulting in the higher computational efficiency of the algorithm. Aside from this, the obtained solution has optimal characteristics from two different viewpoints (qualitative and quantitative perspectives), resulting in a promising and reliable design for the HES.

The rest of the paper is organized as follows: section 2 describes the proposed methodology, including battery performance, the weighted Ah throughput model, the estimation of the stress factors estimation, and the suggested improvements for the traditional GA formulation. In section 3, the proposed approach is illustrated by analyzing an HES to be installed in Zaragoza, Spain. Finally, in section 4, general conclusions are presented and discussed. 


\section{Lead-acid battery lifetime}

Determining lead-acid battery lifetime is a difficult task that depends on the energy sources of the system, the battery technology, and other environmental conditions. Aside from the methods already implemented in the frequently used computational tools previously described, other techniques can be found in the technical literature. In [14], the impact of ambient temperature on battery lifetime was experimentally investigated for both float service and cycling conditions. On the one hand, when BSS works as a backup power supply (float service operation), its lifetime is highly influenced by the corrosion of the positive grid, which increases with temperature. On the other hand, during cycling operation, battery lifetime reduction is basically related to time at low SOC, $A h$-throughput, charge factor, and time between full charges. Among the most relevant results, a methodology based on the definition and cumulative addition of deterioration degrees was developed and verified to determine battery lifetime under variable temperature and float service operating conditions. Aside from this, the negative influence of the increment of discharging currents on battery lifetime was observed, shortening battery lifetime by between onesixth and one-third.

Focusing specifically on the control of electronic equipment and hybrid electric vehicles, in [15] a partially linearized battery model was developed. Based on generalpurpose efficiency curves obtained from the experimental analysis of different BSS technologies such as lead-acid, lithium-ion, and nickel-metal hydride, a logarithmic behavior was intuitively recognized and numerically fitted by means of a nonlinear least-squares regression process. With regard to battery lifetime estimation, it was carried using a downscaling procedure on power loads. Stratifiability Index (SI) was recently presented in [16]; this was created to characterize the acid stratification in terms of the speed of its evolution and the degree of its influence on the battery ageing mechanism; hence, the proper battery type and operation strategy for minimizing the acid stratification could be addressed effectively. In order to estimate the value of SI, two different measurements at the bottom and at the top of the electrode are required. The index is zero if both density measurements have the same value. By contrast, if acid is highly concentrated at the bottom and there is pure water at the top, the SI reaches its maximum value. In this way, the strength of acid stratification in the battery cell is quantified. Similar to the Hybrid2 program, in [17] a method based on the Rain Flow counting approach was developed to incorporate the effects of ambient temperature on ageing. Using DOD and a temperature time series obtained from a computational simulation, operating cycles are extracted by taking their amplitude and duration into account. Then, the ageing rate of each cycle is determined, and its cumulative impact on the battery cell is finally used to determine the end of its life. In [18], an ageing model to be applied to lithium-ion batteries that operates under shallow-depth discharge was presented. Based on a systematic experimental analysis, the effects of temperature, discharge rate, battery voltage, and DOD on battery lifetime were carefully analyzed. Then, a multifactor model was developed using a nonlinear regression analysis based on the Arrhenius correlation. In this research, the weighted Ah ageing model [19-21] has been adopted and combined with other stress factors in order to improve the computational efficiency of GA frequently used for HES design. However, the previously mentioned methodologies for estimating battery lifetime and describing its ageing mechanism could be implemented to reach the same objective.

\subsection{Weighted Ah ageing model}


In this approach, the amount of $A h$ discharged from the battery cell is weighted according to the corresponding operating conditions. The values of the weighting factors increase to represent the severity of the operating situation in terms of the corrosion of the positive grid and the degradation of the active mass. For a determined time instant $(t)$ under analysis, the performance of the battery cell in terms of voltage, current, and the SOC is estimated; then, using this information, the corrosion of the positive grid and the degradation of the active mass are studied quantitatively by means of several weighting factors $[19,21]$. These procedures are described in detail in the next subsections.

\subsubsection{Estimation of a single-cell performance}

The operating situation of a battery cell could be determined by means of the voltage at its terminals, the battery current, and the SOC. The battery voltage is calculated using a modified version of the Shepherd model, which considers the effects of open circuit voltage, the SOC, ohmic losses, and the condition of overvoltage. Voltage equations for charging and discharging conditions are presented in (1)-(2) [1921].

$$
\begin{gathered}
U_{(t)}=U_{0}-g D O D_{(t)}+R_{(t)}^{c}\left(\frac{I_{(t)}}{C_{10}}\right)+R_{(t)}^{c} M_{c}\left(\frac{I_{(t)}}{C_{10}}\right)\left(\frac{S O C_{(t)}}{C_{c}-S O C_{(t)}}\right) \\
\ngtr I_{(t)}>0 \mid t=1, \ldots, T ; \\
U_{(t)}=U_{0}-g D O D_{(t)}+R_{(t)}^{d}\left(\frac{I_{(t)}}{C_{10}}\right)+R_{(t)}^{d} M_{d}\left(\frac{I_{(t)}}{C_{10}}\right)\left(\frac{D O D_{(t)}}{C_{(t)}^{d}-D O D_{(t)}}\right) \\
\ngtr I_{(t)} \leq 0 \mid t=1, \ldots, T .
\end{gathered}
$$

Gassing process represent an important limitation for charge acceptance, meaning that it should be taken into account when estimating the amount of energy effectively stored on the battery. Considering the influence of the gassing phenomenon, the SOC is presented in (3), where the charging current shown in (4) is subtracted from the charging current of the battery [19-21].

$$
\begin{gathered}
S O C_{(t)}=S O C_{(t-\Delta t)}+\int_{t-\Delta t}^{t}\left\{\frac{I_{(\tau)}-I_{(\tau)}^{G}}{C_{10}}\right\} d \tau \ngtr t=1, \ldots, T ; \\
I_{(t)}^{G}=\left(\frac{C_{10}}{100}\right)\left(I_{0(t)}^{G}\right) \exp \left(C_{U}\left[U_{(t)}-U_{0}^{G}\right]+C_{T}\left[T_{(t)}^{a}-T_{0}^{G}\right]\right) \\
\forall I_{(t)}>0 \mid t=1, \ldots, T .
\end{gathered}
$$

\subsubsection{Analysis of the corrosion of the positive grid}

During this analysis, the reduction of battery lifetime as a consequence of the corrosion process is estimated using the Shepherd model to calculate the corrosion voltage, the change in the thickness of the corrosion layer, and the increment of the internal resistance. The corrosion voltage during the charging and discharging processes is presented in (5) and (6), respectively [20,21]. 


$$
\begin{gathered}
U_{(t)}^{c}=U_{0}^{c}-\left(\frac{10}{13}\right) g D O D_{(t)}+R_{(t)}^{c}\left(\frac{I_{(t)}}{2 C_{10}}\right)+R_{(t)}^{c} M_{c}\left(\frac{I_{(t)}}{2 C_{10}}\right)\left(\frac{S O C_{(t)}}{C_{c}-S O C_{(t)}}\right) \\
\forall I_{(t)}>0 \mid t=1, \ldots, T ; \\
U_{(t)}^{c}=U_{0}^{c}-\left(\frac{10}{13}\right) g D O D_{(t)}+R_{(t)}^{d}\left(\frac{I_{(t)}}{2 C_{10}}\right)+R_{(t)}^{d} M_{d}\left(\frac{I_{(t)}}{2 C_{10}}\right)\left(\frac{D O D_{(t)}}{C_{(t)}^{d}-D O D_{(t)}}\right) \\
\ngtr I_{(t)} \leq 0 \mid t=1, \ldots, T .
\end{gathered}
$$

The thickness of the corrosion layer is estimated by taking into account the corrosion speed, which is determined using Arrhenius' law and the relationship between corrosion speed and corrosion voltage proposed by Lander [22]. A mathematical model of the ageing process due to corrosion is presented in (7)-(10) [19,21].

$$
\begin{aligned}
& \Delta W_{(t)}=\left\{\begin{array}{c}
\Delta W_{(t)}=k_{s p}\left(x^{0.6}\right) \mid x=\left[\Delta W_{(t-\Delta t)} /\left(k_{s p}\right)\right]^{\frac{1}{0.6}}+\Delta t ; U_{(t)}^{c}<1.74 \\
\Delta W_{(t)}=\Delta W_{(t-\Delta t)}+\left(k_{s p}\right) \Delta t ; U_{(t)}^{c} \geq 1.74
\end{array}\right. \\
& \Delta R_{(t)}=\Delta R_{\max }\left(\frac{\Delta W_{(t)}}{\Delta W_{\max }}\right) \ngtr t=1, \ldots, T ; \\
& \Delta C_{(t)}^{c}=\Delta C_{\max }^{c}\left(\frac{\Delta W_{(t)}}{\Delta W_{\max }}\right) \ngtr t=1, \ldots, T ; \\
& \Delta W_{\max }=T(F L)\left(k_{\max }^{s p}\right) .
\end{aligned}
$$

\subsubsection{Analysis of the degradation of active mass}

Active mass degradation is mainly due to cycling operation, reaching the maximum DOD, low SOC, among other factors. The influence of the SOC, the time at low SOC, the discharging current, and the number of incomplete charges is represented by the weighting factor in (11), which is calculated using (12)-(14) and the information shown in Figure 1. In Figure 1, full and partial charging conditions are illustrated during the time interval between $t_{A}$ and $t_{B}$ and between $t_{B}$ and $t$, respectively. Each operating period is defined by the value $S O C_{\text {lim }}^{\max }$, which is typically equal to 0.9 . On the one hand, the impact of low SOC is determined by measuring its minimum value during the partial cycling period $\left(\min \left\{S O C_{(t)} \mid \tau \in\left[t_{B}, t\right]\right\}\right)$. On the other hand, the time at low SOC is incorporated through the parameter $\left(\Delta t_{(t)}^{s o c}\right)$, which is the duration of the partial cycling period (13). The influence of the discharging current is included through the current factor $\left(f_{(t)}^{I}\right)$ defined in (12). The discharge current at the beginning of the partial cycling period is assumed to be the most important. The effects of incomplete charges are determined by weighting the amount of full charging $(n)$ by the factor $(\Delta n)$ defined in (14). This weighting parameter depends on the maximum value reached $\left(\max \left\{S O C_{(t)} \mid\left[t_{A}, t_{B}\right]\right\}\right)$, which should be higher than 0.99 in order properly to charge the battery. 


$$
\begin{gathered}
f_{(t)}^{s o c}=1+\left[c_{0}^{s o c}+c_{\min }^{s o c}\left(1-\min \left\{S O C_{(\tau)} \mid \tau \in\left[t_{B}, t\right]\right\}\right) f_{(t)}^{I} \Delta t_{(t)}^{s o c}\right] ; \\
f_{(t)}^{I}=\left(\sqrt{\frac{I_{r}}{I_{(t)}^{1 t h}}}\right)\left(\sqrt[3]{\exp \left(\frac{n}{3.6}\right)}\right) ; \\
\Delta t_{(t)}^{s o c}=t-t_{B} \\
\Delta n=\frac{0.0025-\left(0.95-\max \left\{S O C_{(\tau)} \mid \tau \in\left[t_{A}, t_{B}\right]\right\}\right)^{2}}{0.0025} .
\end{gathered}
$$

The degree of acid stratification is quantified using (15), where the corresponding degree is estimated, taking into account the effects of the gassing and diffusion processes defined in (16)-(19). The change in the degree in acid stratification during the partial cycling operation is considered by the factor $\min \left\{S O C_{(t)} \mid \tau \in\left[t_{B}, t\right]\right\}$ in (16), while the decrement in the degree of acid stratification due to the gassing and diffusion processes depends directly on the gassing current $\left(I_{0(t)}^{G}\right)$ and the ambient temperature $\left(T_{(t)}^{a}\right)$. Finally, the net effect of both processes is incorporated into (15) by including the integral factor of the subtraction $\left(\Delta f_{(t)}^{+}-\Delta f_{(t)}^{-}\right)$.

$$
\begin{gathered}
f_{(t)}^{S T}=f_{(t-\Delta t)}^{S T}+\int_{t-\Delta t}^{t}\left(\Delta f_{(\tau)}^{+}-\Delta f_{(\tau)}^{-}\right) d \tau ; \\
\Delta f_{(t)}^{+}=C_{P}\left(1-\min \left\{S O C_{(\tau)} \mid \tau \in\left[t_{B}, t_{C}\right]\right\}\right) \exp \left(-3 f_{(t)}^{S T}\right)\left(\frac{\left|I_{(t)}^{d}\right|}{I_{r}}\right) ; \\
\Delta f_{G(t)}^{-}=C_{M} \sqrt{\frac{100}{C_{10}}}\left(\frac{I_{0(t)}^{G}}{I_{0}^{G}}\right) \exp \left(C_{U}\left[U_{(t)}-U_{r}\right]+C_{T}\left[T_{(t)}^{a}-T_{0}^{G}\right]\right) ; \\
\Delta f_{D(t)}^{-}=\frac{8 D}{\left(Z_{D}\right)^{2}} f_{(t-\Delta t)}^{S} 2^{\left(T_{(t)}^{a}-293.15\right) / 10} ; \\
\Delta f_{(t)}^{-}=\Delta f_{D(t)}^{-}+\Delta f_{G(t)}^{-} .
\end{gathered}
$$

The total impact of acid stratification is quantified through the factor $\left(f_{(t)}^{A}\right)$ in (20), where the discharge current is included as well. The main concept of the weighted Ah ageing model is presented in (21), where the $A h$ discharged at each instant of time is weighted by the SOC and the total acid stratification factors. In (22), the reduction of battery lifetime due to active mass degradation is then calculated based on the weighted Ah of (21). It is important to note that as the weighted- $A h\left(Z_{(t)}^{W}\right)$ increases compared to the term $\left(1.6\left[Z_{I}\right]\right)$, the reduction of battery lifetime increases exponentially toward the end of battery life, as shown in (22). 


$$
\begin{gathered}
f_{(t)}^{A}=1+f_{(t)}^{S T} \sqrt{\frac{I_{r}}{I_{(t)}^{1 t h}}} \forall t=1, \ldots, T ; \\
Z_{(t)}^{W}=\frac{1}{C_{10}} \int_{0}^{t}\left|I_{(t)}^{d}\right| f_{(t)}^{s o c} f_{(t)}^{A} d t \ngtr t=1, \ldots, T ; \\
\Delta C_{(t)}^{d}=\Delta C_{\text {max }}^{d} \exp \left(-C_{Z}\left\{1-\frac{Z_{(t)}^{W}}{1.6\left[Z_{I}\right]}\right\}\right) \forall t=1, \ldots, T .
\end{gathered}
$$

The impact of the operating conditions on battery parameters such as internal resistance, gassing current, and battery capacity are shown in (23)-(26) [19,21].

$$
\begin{gathered}
R_{(t)}^{c}=R_{(0)}^{c}+\Delta R_{(t)} \ngtr t=1, \ldots, T ; \\
R_{(t)}^{d}=R_{(0)}^{d}+\Delta R_{(t)} \ngtr t=1, \ldots, T ; \\
I_{0(t)}^{G}=I_{0}^{G}+\Delta I_{0}^{G}\left(\frac{\Delta R_{(t)}}{\Delta R_{\max }}\right) \ngtr t=1, \ldots, T ; \\
C_{(t)}^{d}=C_{(0)}^{d}-\Delta C_{(t)}^{c}-\Delta C_{(t)}^{d} \ngtr t=1, \ldots, T .
\end{gathered}
$$

The simulation procedure of the weighted Ah ageing model is presented in Figure 2, where for each instant of time, battery performance is evaluated using (1)-(4). These results are then used to evaluate the degree of the corrosion of the positive grid using (5)-(10), as well as the degree of battery degradation using (11)-(22). Finally, the influence of these ageing mechanisms on battery parameters is quantified by updating the internal resistance, gassing current, and available capacity using (23)-(26) [19,21].

\section{"See Figure 2"}

Now that the quantitative method to be used in this work has been described, a qualitative approach based on the analysis of several stress factors is presented.

\subsection{Stress factors and the categorization of operating conditions}

The analysis described in this work is based on the interpretation of the charge factor, the $A h$ throughput, the highest discharge rate, the time between full charges, the time at low SOC, and the partial cycling [12,23]. Other stress factors related to the ambient temperature were not taken into account. In the weighted Ah ageing model, the analysis of the battery operating conditions by means of stress factors entails estimating battery performance in terms of the voltage at its terminals, the current, and the SOC. This task has been carried out using (1)-(4) [19,21] and without considering variations in the battery parameters as a consequence of positive grid corrosion and active mass degradation. Then, the time series for each variable is used to determine the magnitude of each stress factor.

\subsubsection{Charge factor}


The charge factor is defined as the inverse of $A h$ efficiency, and it is mathematically expressed in (27) and (28). This stress factor could be used to determine the battery operation (full or partial charging operation) and the adjustments of charge voltage. In addition, depending on its value, it could indicate the ageing mechanisms. If it tends to be very low, the battery could suffer from sulphation, acid stratification, and significant differences between the cells of the battery bank. By contrast, if this factor tends to be very high, the battery could suffer from active mass shedding, water loss, and corrosion. This factor is typically between $102 \%$ and $130 \%[12,23]$.

$$
\begin{gathered}
C F=\frac{A h_{\text {charged }}}{A h_{\text {discharged }}}=-\frac{\int_{t=1}^{T} I_{(t)} H\left(I_{(t)}\right) d t}{\int_{t=1}^{T} I_{(t)} H\left(-I_{(t)}\right) d t} ; \\
H\left(I_{(t)}\right)=\left\{\begin{array}{ll}
0 ; & I_{(t)}<0 \\
1 ; & I_{(t)} \geq 0
\end{array} \forall t=1, \ldots, T .\right.
\end{gathered}
$$

\subsubsection{Ah throughput}

$A h$ throughput is a normalized measure of the $A h$ discharged from the battery throughout the year. This idea is represented mathematically in (29). The total influence of $A h$ throughput on the ageing process requires the simultaneous consideration of the cycling operation at a partial SOC and its corresponding time. This factor is typically between 10 and 100 times the nominal capacity $\left(C_{10}\right)[12,23]$.

$$
Q_{t h r}=\frac{\int_{t=1}^{T} I_{(t)} H\left(I_{(t)}\right)}{C_{10}} .
$$

\subsubsection{Highest discharge rate}

The effects of high discharge currents on battery lifetime are estimated by measuring the highest discharge current, so that $1 \%$ of the yearly $A h$ throughput $\left(Q_{t h r}\right)$ is discharged. This factor allows us to consider the impact of the starting currents of some household appliances on battery ageing [12]. Stress factors related to the highest discharge current $\left(I_{1 \%}^{\max }\right)$ are determined using a histogram similar to that shown in Figure 3, where a determined amount of bins $(m=1, \ldots, M)$ are used to build the discharging current intervals $\left(l_{(m)}\right)$ and to calculate their corresponding frequencies $\left(f_{(m)}\right)$. This histogram is jointly used with (30) and (31) to estimate the stress factor value. More specifically, using Figure 3 and (30), the amount of bins $(L)$ required to fulfill $1 \%$ of the total $A h$ throughput discharged is determined. Then, using this result, the stress factor $\left(I_{1 \%}^{\max }\right)$, which is the average current of all of the bins $(L)$ normalized to the rated discharging current in $10 \mathrm{~h}\left(I_{10}\right)$, is calculated by (31). Frequently, this is factor is below $I_{10}$ [23].

\section{"See Figure 3"}

$$
\sum_{m=M-L}^{M} l_{(m)} f_{(m)}=0.01\left(Q_{t h r}\right) C_{10}
$$




$$
I_{1 \%}^{\max }=\left\{0.01\left(Q_{t h r}\right) C_{10}\right\} /\left\{I_{10}\left(\sum_{m=M-L}^{M} l_{(m)} f_{(m)}\right)\right\} .
$$

\subsubsection{Time between full charges}

The impact of a long time between full charges is measured in an average by determining the number of operating cycles and their duration when the SOC remains at a value lower or equal to $S O C_{\text {lim }}^{\max }=0.9$. This idea is expressed mathematically in (32). The number of cycles $\left(C_{F}\right)$ is determined by recognizing the changes in the SOC from a value lower or equal to $S O C_{\text {lim }}^{\max }$ in the time instant $(t-\Delta t)$ to another one higher than $S O C_{\text {lim }}^{\max }$ at the current time instant $(t)$. This factor is frequently between 0.7 days and 10 days [23].

$$
T_{F}=\left\{\int_{t=1}^{T} H\left(S O C_{\text {lim }}^{\max }-S_{(t)}\right) d t\right\} /\left\{24\left(C_{F}\right)\right\} .
$$

\subsubsection{Time at low SOC}

In this stress factor, the operational conditions at which the SOC is below $S O C_{\text {lim }}^{\text {low }}=0.35$ are considered in relation to the increase of battery sulphation. This is defined mathematically in (33), and it is typically between $0 \%$ and $50 \%$ [23].

$$
T_{S}=100\left\{\int_{t=1}^{T} H\left(S O C_{\text {lim }}^{\text {low }}-S O C_{(t)}\right) / T\right\} .
$$

\subsubsection{Partial cycling}

This stress factor incorporates the effects of $A h$ discharging at a determined SOC value. This analysis is carried out by estimating the $A h$ discharged during each of the five SOC categories defined in Table 1. First, the partial cycling for each SOC range is estimated by using (34). Then, using these results, a unified factor is estimated through the evaluation of (35). It is important to note how those SOC ranges with low values have a higher weight on the partial cycling stress factor. The partial cycling factor is typically between $20 \%$ and $70 \%$ [23].

$$
\begin{gathered}
P_{(l)}=-\left\{\int_{t=1}^{T} I_{(t)} H\left(P_{(l)}^{\min }-S O C_{(t)}\right) H\left(P_{(l)}^{\max }-S O C_{(t)}\right) H\left(-I_{(t)}\right) d t\right\} /\left\{\int_{t=1}^{T} I_{(t)} H\left(-I_{(t)}\right) d t\right\} \\
\forall l=A, B, C, D, E \\
\text { "See Table 1" } \\
P C=\left\{P_{(A)}+2\left[P_{(B)}\right]+3\left[P_{(C)}\right]+4\left[P_{(D)}\right]+5\left[P_{(E)}\right]\right\} / 5
\end{gathered}
$$

\subsection{Efficient and optimal design of hybrid energy systems}

Due to its flexibility and its intrinsic ability to provide a near-optimal solution to complex optimization problems, heuristic techniques such as GA have become very popular for the design and control of HESs. An example can be found in [24], where a 
GA was implemented in order to design an HES, taking into account Cost of Energy (COE) and Greenhouse Gas (GHG) emissions as the main variables of a multiobjective optimization problem. Similarly, in [25], a multiobjective optimization model capable of considering the cost related to battery life reduction-among other cost factors such as initial investments, Operation and Maintenance (O\&M) costs, and GHG emissionswas formulated and solved by a GA in order to improve the operating performance of an HES installed in China. Aside from GA, other techniques such as particle swarm optimization and simulated annealing, among other methodologies, have been suggested [26].

In general, the optimization of HESs by GA requires the adoption of an integer codification system to consider all of the technical characteristics of each element and its corresponding manufacturer. In our case, each individual is composed of four chromosomes represented by the vector (36) and belonging to the population represented by the matrix (37). All of the manufacturers of Wind Turbine (WTs) and battery cells are listed in two different tables. A determined WT manufacturer is considered in the analysis by means of its position (row) on the table, which is assigned to the variable $\left(k_{(S)}^{1}\right)$, the maximum number of wind turbines connected in parallel is considered in the variable $\left(k_{(S)}^{2}\right)$. A determined battery manufacturer is considered in the analysis by means of its position (row) on the corresponding table, which is assigned to the variable $\left(k_{(S)}^{3}\right)$, and the maximum number of batteries connected in parallel (strings) is taken into account by the variable $\left(k_{(S)}^{4}\right)$.

$$
\begin{aligned}
& \vec{k}_{(s)}=\left[\begin{array}{llll}
k_{(s)}^{1} & k_{(s)}^{2} & k_{(s)}^{3} & k_{(s)}^{4}
\end{array}\right] \ngtr s=1, \ldots, S ; \\
& K=\left[\begin{array}{c}
\vec{k}_{(1)} \\
\vdots \\
\vec{k}_{(s)} \\
\vdots \\
\vec{k}_{(S)}
\end{array}\right] .
\end{aligned}
$$

The GA for the efficient design of an HES is carried out by following the procedure described below.

Step 1: Using an integer random number generator, variables $k_{(s)}^{1}, k_{(s)}^{2}, k_{(s)}^{3}$, and $k_{(s)}^{4}$ with $s=1, \ldots, S$ are independently obtained. The types and maximum number of WTs and battery cells are taken into account by introducing the following constraints for the random-number generation: $k_{\text {min }}^{1} \leq k_{(s)}^{1} \leq k_{\max }^{1}, k_{\min }^{2} \leq k_{(s)}^{2} \leq k_{\max }^{2}, k_{\min }^{3} \leq k_{(s)}^{3} \leq$ $k_{\max }^{3}$, and $k_{\min }^{4} \leq k_{(s)}^{4} \leq k_{\max }^{4}$. Thus, the population to be evaluated during the first generation is prepared.

Step 2: The index to represent the generation under analysis is set to $1(v \leftarrow 1)$.

Step 3: At this stage, the NPC and Energy Index of Unreliability (EIU) should be estimated for each individual in the population by means of a long-term simulation of the HES using the weighted Ah throughput method. However, this is a time-consuming task because the HES is simulated for the entirety of its battery lifetime, which could be longer than one year. In order to increase the efficiency of the optimization algorithm, 
first, the stress factors of the operating conditions obtained from a yearly simulation are performed by means of (1)-(4) and (27)-(35) described in subsections 2.1 and 2.2. If these factors indicate operational behavior similar to that of an optimal-designed Solar Home System (SHS) (Table 2, from the qualitative perspective of an expert), then the weighted Ah throughput method of (1)-(4) and (5)-(26) described in subsection 2.1 is applied in order to estimate the battery lifetime required to calculate the NPC. In other words, once the evaluation of the stress factors has been carried out, if they are higher than the reference values shown in Table 2, the weighted Ah throughput method is not used due to the healthy operation of battery bank is not possible. In those cases, when the HES is not simulated, and also in the cases when the HES is simulated with a result of EIU higher than the required value; it means, Energy Not Supplied (ENS) higher than the value allowed by the system designer, an arbitrarily high value of NPC is assigned $(\mathrm{NPC} \rightarrow \infty)$. The values presented in Table 2 and to be used as a reference were taken from the analysis of an optimally designed SHS analyzed in [23] (specifically, Category 5: Optimal SHS).

\section{"See Table 2"}

Step 4: In this step, the fitness of each individual in the population is determined by applying (38).

$$
F_{f(s)}=\frac{(S+1)-s}{\sum_{w=1}^{S}\{(S+1)-w\}} \ngtr s=1, \ldots, S .
$$

Step 5: Perform reproduction, crossing, and mutation procedures.

Step 6: If $(v<V)$, then $v \leftarrow v+1$ and go to step 3. Otherwise, stop.

\section{Case study}

In this section, the methodology proposed in this work is illustrated by analyzing an HES to be installed in Zaragoza, Spain, composed of a battery bank, a charge controller, a WT, and a bidirectional converter. The information related to the meteorological conditions of wind resources and ambient temperature comes from the Spanish Meteorological Agency [27]. The mathematical model of the charge controller, the wind generator, and the bidirectional converter can be found in [28]. The load demand to be supplied is shown in Figure 4, it is assumed to be the result of the daily operation of several household appliances installed in a typical rural house. The battery cells and WTs considered in the optimization process are shown in Tables 3 and 4, where each manufacturer is indicated through the corresponding index, among other technical parameters such as rated capacity and lifetime. The rated capacity of the bidirectional converter was assumed to be $300 \mathrm{~W}$ with a lifetime of 10 years, hence the can be effectively supplied. All of the parameters required to model battery cell were assumed to be typical ones (presented on the list of symbols) and can be found in $[19,21]$, whereas some data related to the techno-economic analysis and optimization process such as inflation and discount rates, project lifetime, as well as number of generations, population size, crossover and mutation rates are presented in Table 5. The costs related to the acquisition and O\&M of all of the elements were estimated from the recently published information available in [29]. 


\author{
"See Table 3" \\ "See Table 4" \\ "See Table 5" \\ "See Figure 4"
}

As can be noted from Tables 3 and 4 and from the maximum amount of strings, the total amount of the combination is not significantly high; hence, the global optimum could easily be achieved by applying an enumerative method. The quantitative and qualitative ageing models presented in section 2 were implemented in MATLAB ${ }^{\circledR}$ in a standard personal computer with an i7-3630QM CPU at $2.40 \mathrm{GHz}, 8 \mathrm{~GB}$ of RAM, and a 64-bit operating system. Figure 5 shows the evolution of the implemented GA obtaining a near-optimal solution in 20 iterations of the optimization algorithm; the corresponding results have been compared to the enumerative optimization method and shown in Table 6. The performance of this near-optimal solution in terms of the evolution of lifetime cycles, the loss of battery life, the SOC, and the impact of corrosion and degradation phenomena are shown in Figures 6-11. In Figure 6, the difference between the weighted and unweighted cycles could be clearly observed, unweighted cycles are frequently used to the estimation of battery lifetime in several computational tools due to its very limited complexity and easy implementation; however, according to these results, this factor is not enough to effectively describe the loss of life on the battery system. The reduction on battery capacity is shown in Figure 7; the evolution of SOC is presented in Figure 8, while the effects of degradation and corrosion are shown in Figures 9 and 10, respectively. In Figure 7, it is possible to observe a slow reduction on battery life during the first two years as a consequence of the corrosion process (Figure 10); after this period, loss of battery lifetime is highly influenced by the degradation process (Figure 9), speeding the loss of capacity in 4.2 years. Figure 11 shows the evolution of battery current per cell; reader can note a reduction on the battery current as a consequence of the constant increment on the internal resistance of each cell due to the corrosion phenomenon. The stress factor analysis for the configuration obtained by GA is presented in Figure 12 and Table 7 by showing the estimation of the corresponding stress factors and their categorization by means of a radar plot.

From Table 6, it is possible to observe how both solutions (those obtained by the GA and by the enumerative method) have similar characteristics, suggesting a WT of $5 \mathrm{~kW}$ and a battery bank of $110.976 \mathrm{kWh}$ if the GA method is used, and $110.4 \mathrm{kWh}$ if the enumerative method is employed. With respect to battery lifetime, there is a difference of $26.1 \%$, which directly influences the NPC by $4.8 \%$. Something interesting occurs with HES reliability. As stated before, the required EIU was 1\% (Table 5); however, the EIU estimated for the configuration obtained from the GA method is slightly higher due to the fact that the estimation of stress factors is carried out without taking into account the changes in the internal resistance and the gassing current, which impact the amount of energy that could be stored in the battery bank and, consequently, the estimation of the EIU. With regard to the qualitative viewpoint, according to the radar plot in Figure 12 and the information in Table 7, the risk level for the reduction of battery life is between low and high. The stress factor with a high level of risk is related to the time between full charges and due to the fact that the SOC is between medium and high values (Figure 8). Otherwise, as any peak load was assumed to be connected 
due to the ideality of the case study (the load demand is strictly based on Figure 4), the estimated risk level related to the highest discharge current results in a very low value.

\author{
"See Table 6" \\ "See Figure 5" \\ "See Figure 6" \\ "See Figure 7" \\ "See Figure 8" \\ "See Figure 9" \\ "See Figure 10” \\ "See Figure 11" \\ "See Table 7" \\ "See Figure 12"
}

According to the results presented in Table 6, the storage system and wind generator have important effect due to the limited wind resources at the location under analysis. This can be observed in Figure 13, where the wind power time series and its corresponding histogram are shown. The power produced by the WT is low and with a high frequency, which is a direct consequence of the limited wind resources and the capabilities of the WT. In order to supply the load requirements during those periods of time without abundant wind resources, and to maintain the SOC within a reasonable range to prolong battery life, an HES with a WT of high rated power combined with a storage system of high capacity should be installed.

"See Figure 13”

\title{
4. Conclusions
}

Due to the importance of HESs for rural electrification and microgrid applications, optimal design that incorporates battery cell ageing mechanisms is an important and difficult task. In this paper, the weighted Ah ageing model and stress factor categorization are combined with a traditional integer-coded GA in order to improve the computational efficiency. Thus, a near-optimal solution evaluated from quantitative and qualitative perspectives is obtained. The proposed method was illustrated by analyzing an HES to be installed in Zaragoza, Spain. According to the obtained results, it is likely that the battery bank will need to be replaced in 4.2 years due to the operation at a medium to high SOC during a relatively long amount of time. In general, the combination of quantitative and qualitative methods in the analysis and planning of HESs could improve the understanding of its behavior and the selection of the cost-effective options for sustainable electrification. 


\section{Acknowledgments}

This work was supported by FEDER funds through COMPETE and by Portuguese funds through FCT, under FCOMP-01-0124-FEDER-020282 (PTDC/EEAEEL/118519/2010), UID/CEC/50021/2013 and SFRH/BPD/103079/2014. Moreover, the research leading to these results has received funding from the EU Seventh Framework Programme FP7/2007-2013 under grant agreement no. 309048. This work was also supported by the Ministerio de Economía y Competitividad of the Spanish Government under Project ENE2013-48517-C2-1-R.

\section{References}

[1] Ogunjuyigbe ASO, Ayodele TR, Akinola OA. Optimal allocation and sizing of PV/Wind/Split-diesel/Battery hybrid energy system for minimizing life cycle cost, carbon emission and dump energy of remote residential building. Appl Energ 2016;171:153-171.

[2] Korkas CD, Baldi S, Michailidis I, Kosmatopoulos EB. Occupancy-based demand response and thermal comfort optimization in microgrids with renewable energy sources and energy storage. Appl Energ 2016;163:93-104.

[3] Ansari AB, Esfahanian V, Torabi F. Discharge, rest and charge simulation of leadacid batteries using an efficient reduced order model based on proper orthogonal decomposition. Appl Energ 2016;173:152-167.

[4] Dufo-López E, Lujano-Rojas JM, Bernal-Agustín JL. Comparison of different leadacid battery lifetime prediction models for use in simulation of stand-alone photovoltaic systems. Appl Energ 2014;115:242-253.

[5] Sauer DU, Wenzl H. Comparison of different approaches for lifetime prediction of electrochemical systems-using lead-acid batteries as example. J Power Sources 2008;176:534-546.

[6] Wenzl H, Baring-Gould I, Kaiser R, Liaw BY, Lundsager P, Manwell J, Ruddell A, Svoboda V. Life prediction of batteries for selecting the technically most suitable and cost effective battery. J Power Sources 2005;144:373-384.

[7] Sinha S, Chandel SS. Review of software tools for hybrid renewable energy systems. Renew Sust Energ Rev 2014;32:192-205.

[8] Lambert T, Gilman P, Lilienthal P. Micropower system modeling with HOMER. In: Farret FA, Simões MG, editors. Integration of alternative sources of energy. NJ, USA: John Wiley \& Sons Inc; 2006. p. 379-418.

[9] Walker M. HOMER Optimizer ${ }^{\mathrm{TM}}$, a faster path to finding least-cost microgrid options. Available at: www.microgridnews.com

[10] iHOGA website. Available at: http://personal.unizar.es/rdufo/index.php?lang=en 
[11] Manwell JF, Rogers A, Hayman G, Avelar CT, McGowan JG. Hybrid2: A hybrid system simulation model: Theory manual. Renewable Energy Research Laboratory University of Massachusetts and National Renewable Energy Laboratory; 1998.

[12] RESDAS website. Available at: https://www.ecn.nl/resdas/

[13] Baring-Gould EI, Wenzl H, Kaiser R, Wilmot N, Mattera F, Tselepis S, Nieuwenhout F, Rodrigues C, Perujo A, Ruddell A, Lundsager P, Bindner H, Cronin T, Svoboda V, Manwell J. Detailed evaluation of renewable energy power system operation: A summary of the European Union hybrid power system Component benchmarking project. National Renewable Energy Laboratory; 2005.

[14] Tsujikawa T, Matsushima T, Yabuta K, Matsushita T. Estimation of the lifetimes of valve-regulated lead-acid batteries. J Power Sources 2009;187:613-619.

[15] Agarwal V, Uthaichana K, DeCarlo RA, Tsoukalas LH. Development and validation of a battery model useful for discharging and charging power control and lifetime estimation. IEEE Trans Energy Convers 2010;25:821-835.

[16] Schulte D, Sauer DU, Ebner E, Börger A, Gose S, Wenzl H. "Stratifiability index"A quantitative assessment of acid stratification in flooded lead acid batteries. J Power Sources 2014;269:704-715.

[17] Layadi TM, Champenois G, Mostefai M, Abbes D. Lifetime estimation tool of lead-acid batteries for hybrid power sources design. Simul Model Pract Th 2015;54:3648.

[18] Cui Y, Du C, Yin G, Gao Y, Zhang L, Guan T, Yang L, Wang F. Multi-stress factor model for cycle lifetime prediction of lithium ion batteries with shallow-depth discharge. J Power Sources 2015;279:123-132.

[19] Bindner H, Cronin T, Lundsager P, Manwell JF, Abdulwahid U, Baring-Gould I. Lifetime modelling of lead acid batteries. Denmark National Laboratory Ris $\varnothing ; 2005$.

[20] Andersson A. Battery lifetime modelling. Denmark National Laboratory Ris $\varnothing$; 2006.

[21] Schiffer J, Sauer DU, Bindner H, Cronin T, Lundsager P, Kaiser R. Model prediction for ranking lead-acid batteries according to expected lifetime in renewable energy systems and autonomous power-supply systems. J Power Sources 2007;168(1):66-78.

[22] Lander JJ. Further studies on the anodic corrosion of lead in $\mathrm{H}_{2} \mathrm{SO}_{4}$ solutions. $\mathbf{J}$ Electrochem Soc 1956;103(1):1-8.

[23] Svoboda V, Wenzl H, Kaiser R, Jossen A, Baring-Gould I, Manwell J, Lundsager P, Bindner H, Cronin T, Nørgård P, Ruddell A, Perujo A, Douglas K, Rodrigues C, Joyce A, Tselepis S, van der Borg N, Nieuwenhout F, Wilmot N, Mattera F, Sauer DU. Operating conditions of batteries in off-grid renewable energy systems. Sol Energy 2007;81(11):1409-1425. 
[24] Katsigiannis YA, Georgilakis PS, Karapidakis ES. Multiobjective genetic algorithm solution to the optimum economic and environmental performance problem of small autonomous hybrid power systems with renewables. IET Renew Power Gen 2010;4(5):404-419.

[25] Zhao B, Zhang X, Chen J, Wang C, Guo L. Operation optimization of standalone microgrids considering lifetime characteristics of battery energy storage system. IEEE Trans Sustain Energy 2013;4(4):934-943.

[26] Sinha S, Chandel SS. Review of recent trends in optimization techniques for solar photovoltaic-wind based hybrid energy systems. Renew Sust Energ Rev 2015;50:755769.

[27] Agencia Estatal de Meteorología (Meteorological Agency). http://www.aemet.es/es/portada

[28] Lujano-Rojas JM, Dufo-López R, Bernal-Agustín JL. Probabilistic modelling and analysis of stand-alone hybrid power systems. Energy 2013;63:19-27.

[29] Dufo-López R, Cristóbal-Monreal IR, Yusta MJ. Optimisation of PV-wind-dieselbattery stand-alone systems to minimize cost and maximize human development index and job creation. Renew Energ 2016;94:280-293. 


\section{Figure caption}

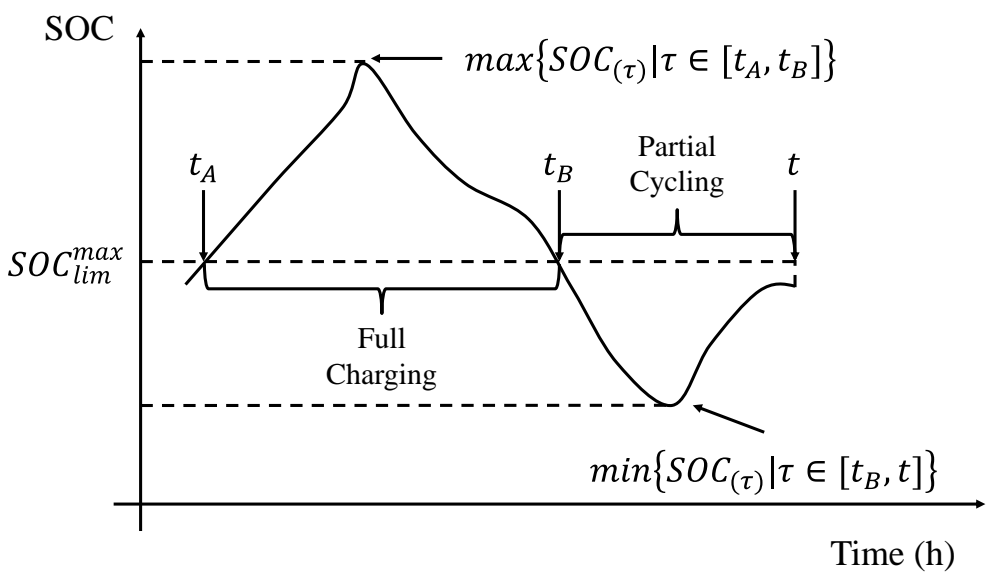

Fig. 1: Description of full charging and partial charging operation.

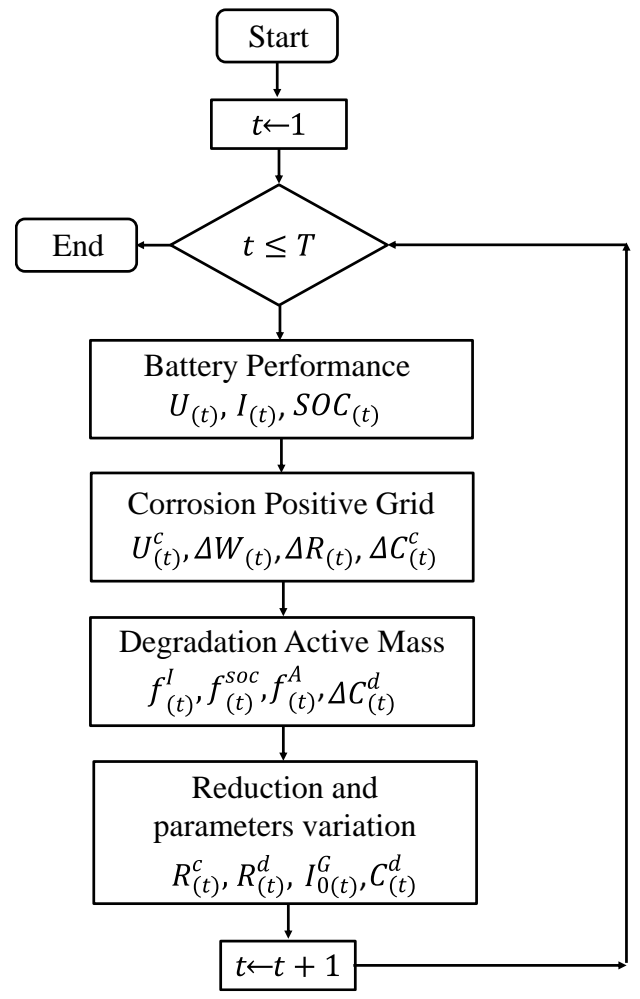

Fig. 2: Calculation of battery performance by weighted Ah ageing model. 


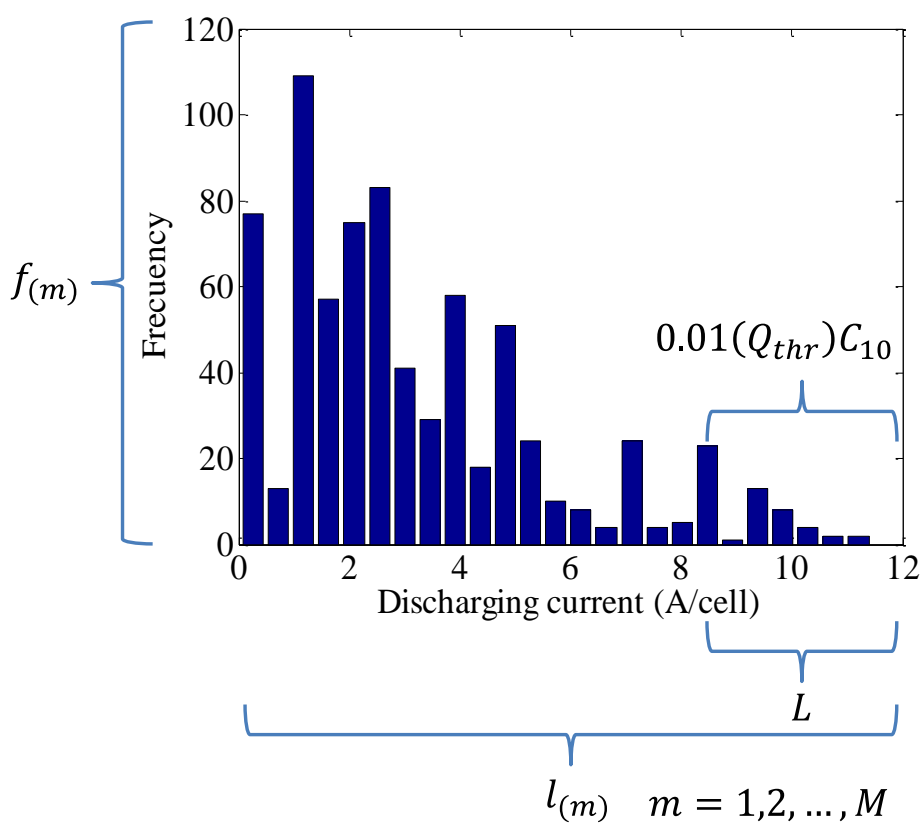

Fig. 3: Histogram of frequency of the discharged current.

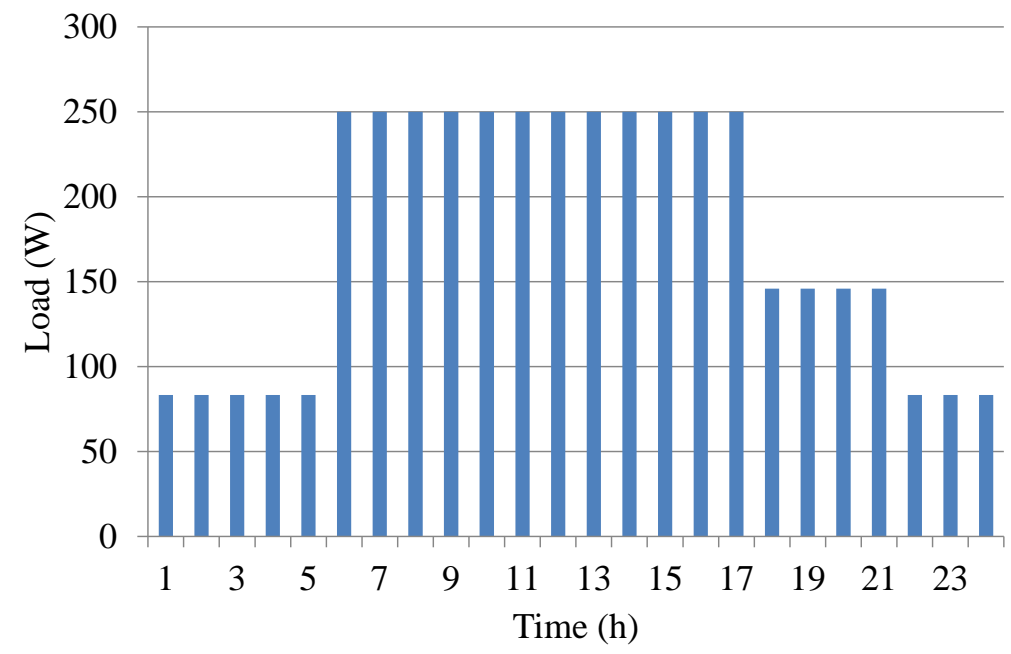

Fig. 4: Hourly load profile of the system. 


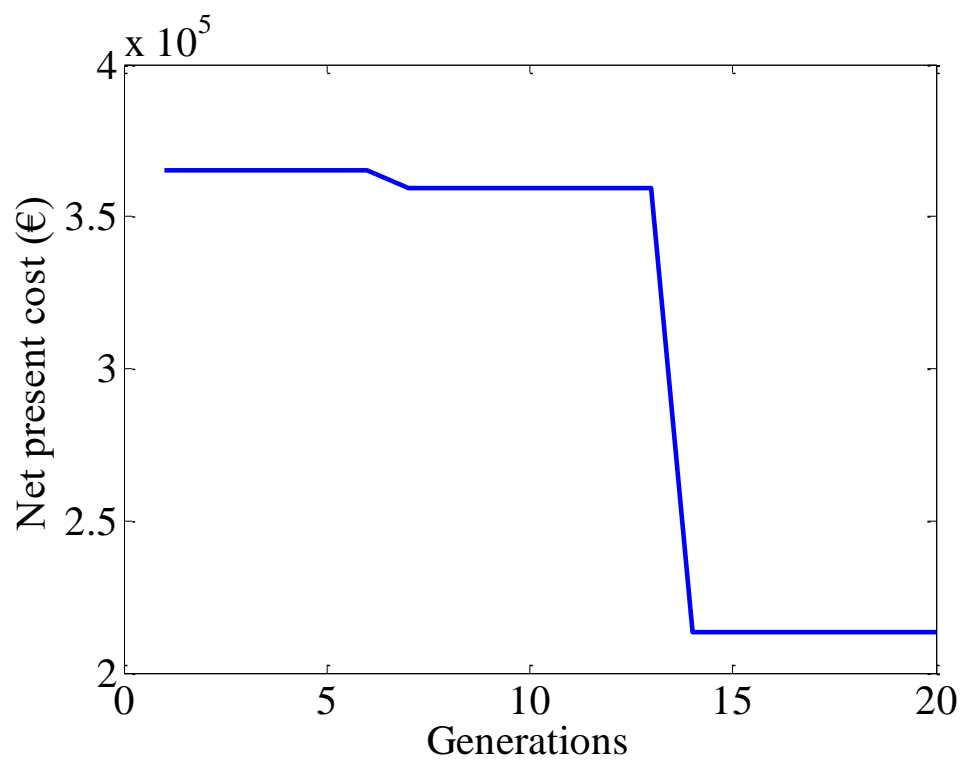

Fig. 5: Performance of GA.

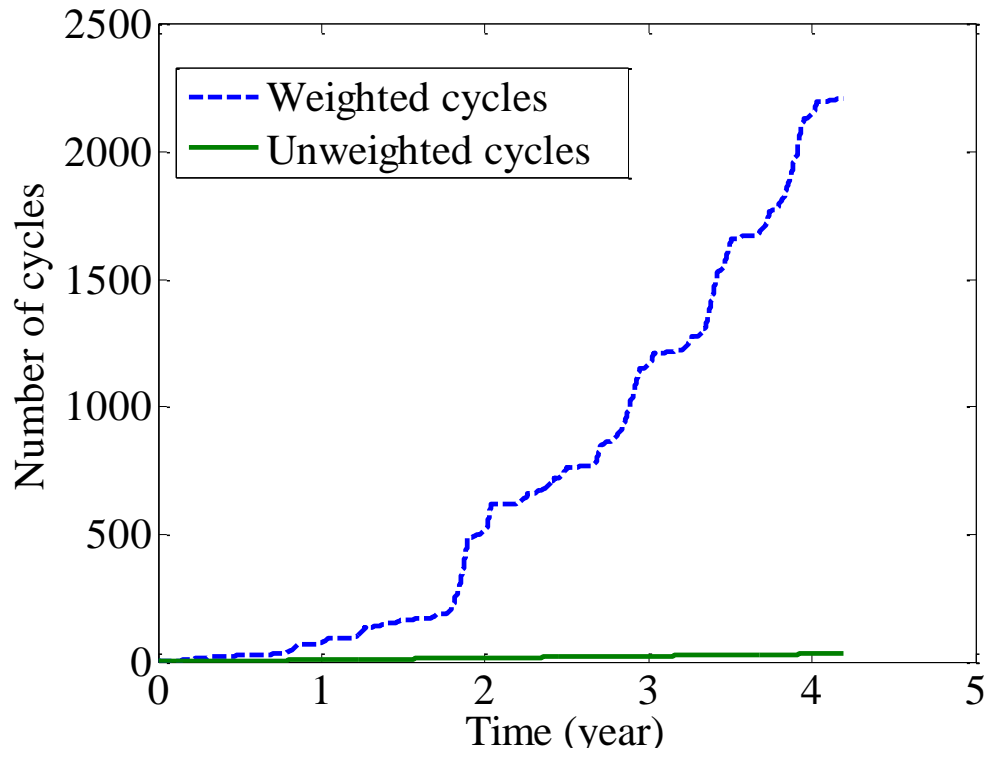

Fig. 6: Evolution of life cycles with the time. 


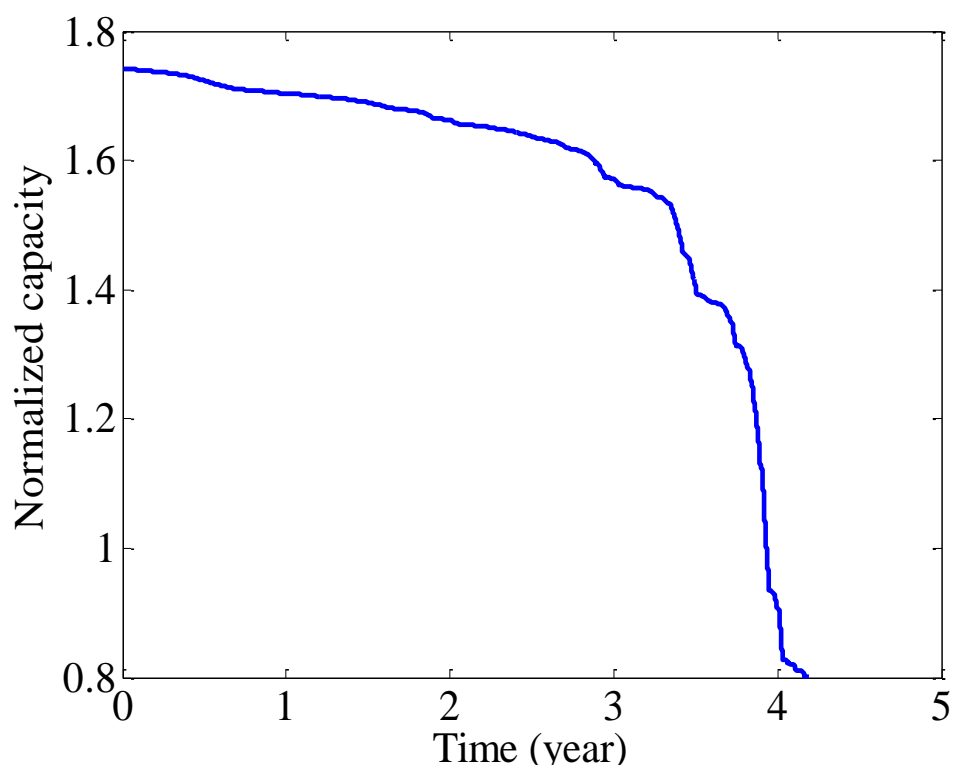

Fig. 7: Reduction of battery capacity with the time.

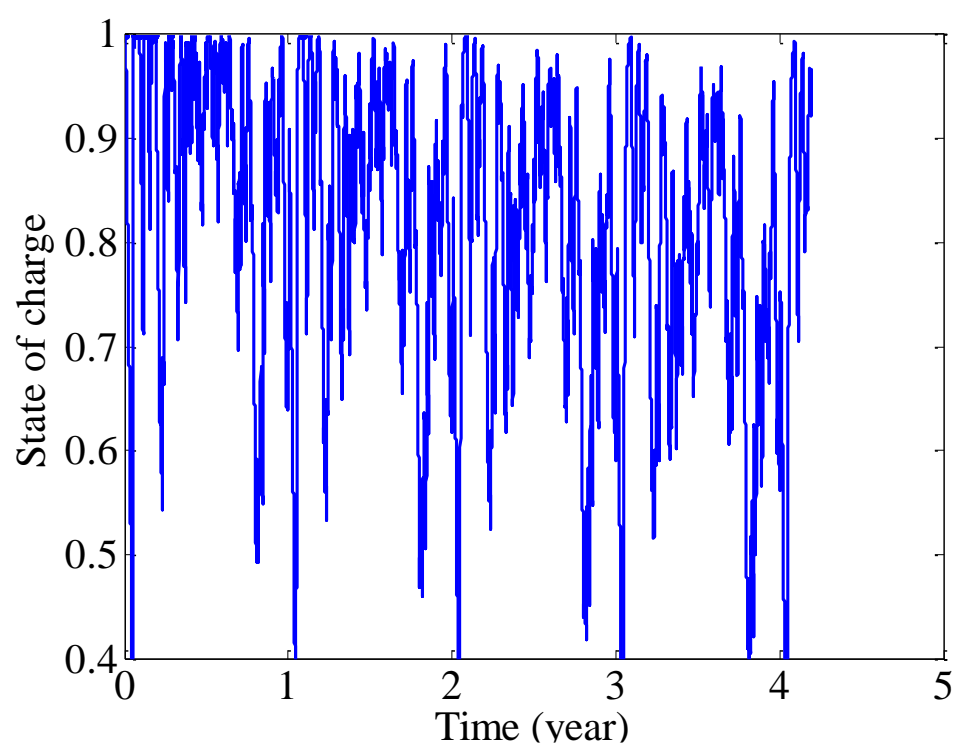

Fig. 8: State of charge through battery lifetime. 


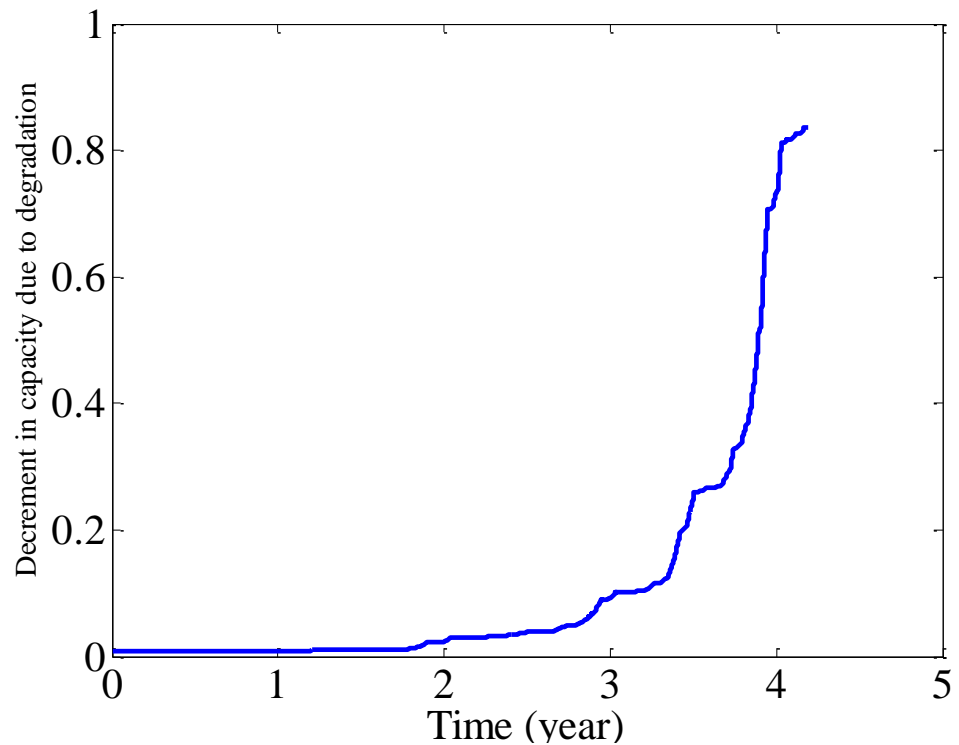

Fig. 9: Effect of degradation process with the time.

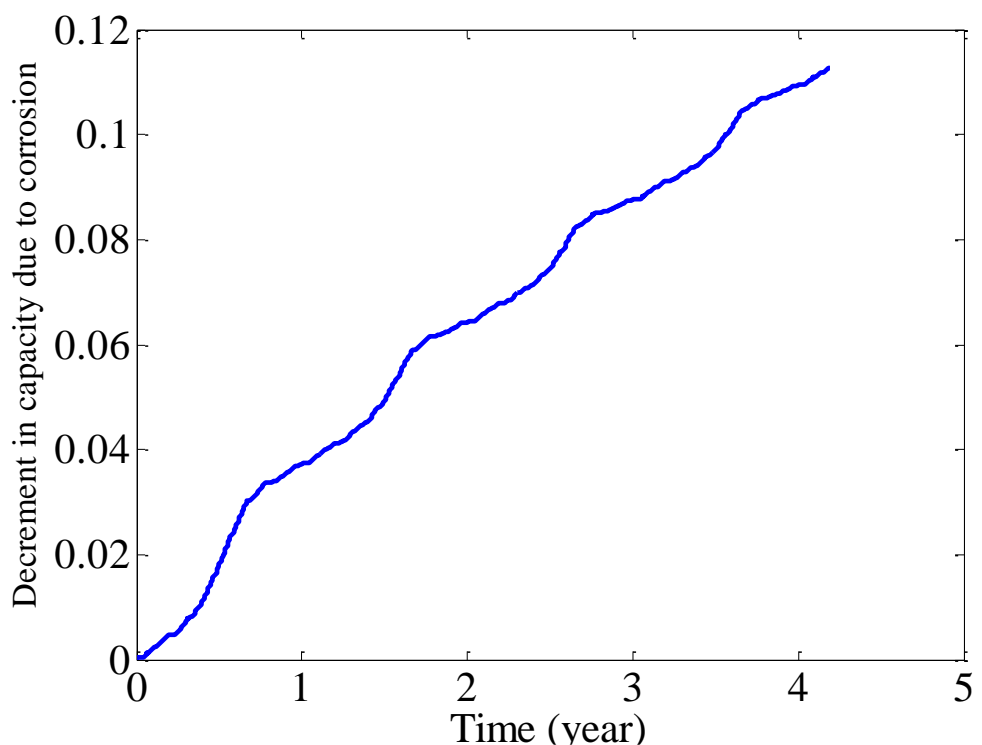

Fig. 10: Effect of corrosion process with the time. 


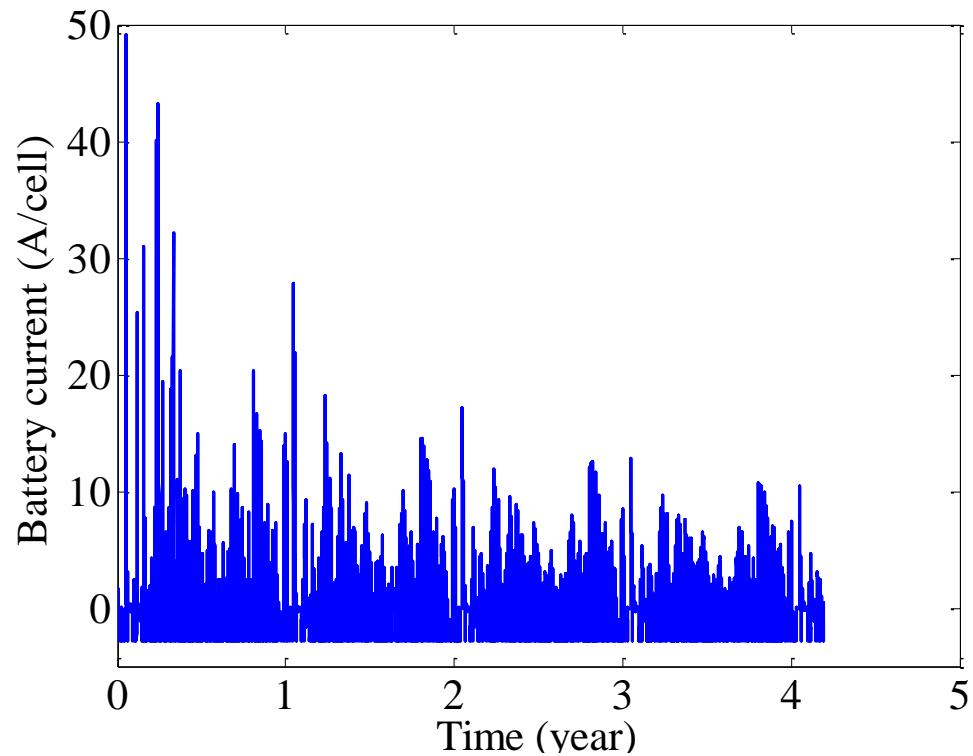

Fig. 11: Battery current through the battery lifetime.

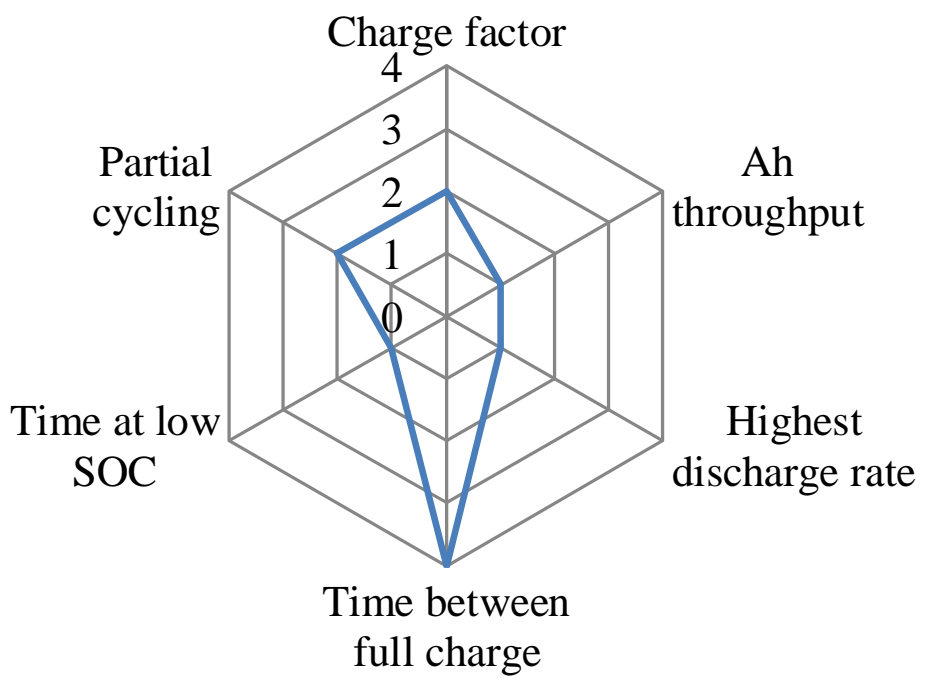

Fig. 12: Radar plot diagram for optimal configuration (1: Very low; 2: Low; 3: Medium; 4: High intensity; 5: Very high intensity). 

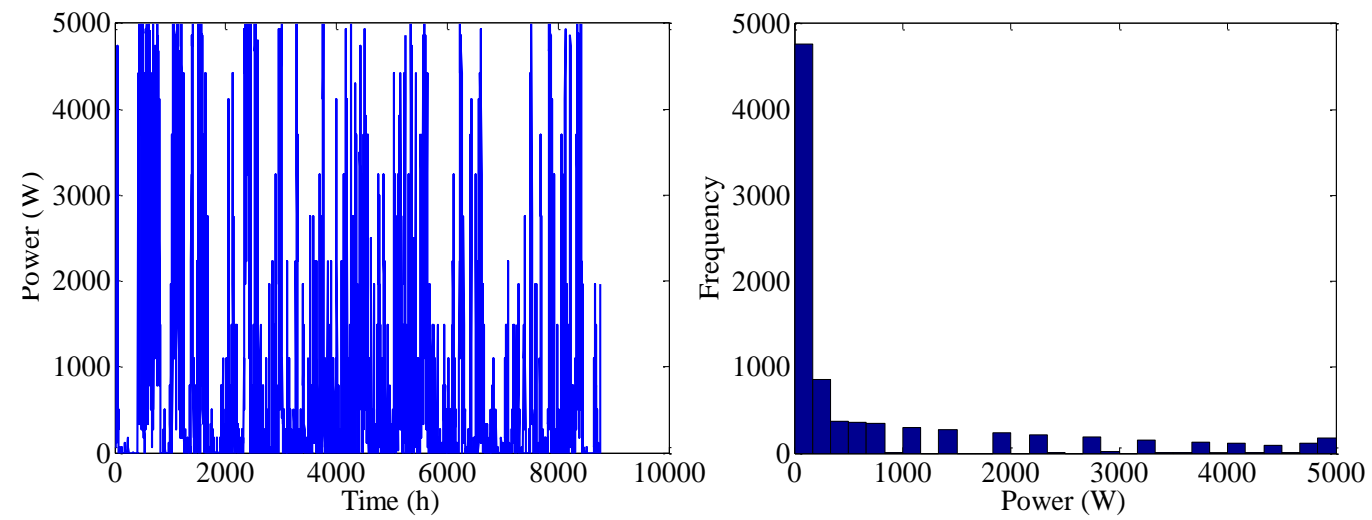

Fig. 13: Power generation of $5000 \mathrm{~W}$ wind turbine. 
Table caption

Table 1: Definition of SOC ranges.

\begin{tabular}{lcc}
\hline$l$ & $P_{(l)}^{\min }$ & $P_{(l)}^{\max }$ \\
\hline$A$ & 0.85 & 1 \\
$B$ & 0.7 & 0.85 \\
$C$ & 0.55 & 0.7 \\
$D$ & 0.4 & 0.55 \\
$E$ & 0 & 0.4 \\
\hline
\end{tabular}

Table 2: Reference values of stress factors and risk levels.

\begin{tabular}{cc}
\hline Stress factor & Value \\
\hline$C F$ & $115 \%$ \\
$Q_{t h r}$ & 70 \\
$I_{1 \%}^{\max }$ & 1.4 \\
$T_{F}$ & 8 days \\
$T_{S}$ & $15.5 \%$ \\
$P C$ & $70 \%$ \\
\hline
\end{tabular}

Table 3: Characteristics of lead-acid batteries considered.

\begin{tabular}{ccccc}
\hline Manufacturer & $C_{10}(\mathrm{Ah})$ & $Z_{I}$ & $S O C_{\min }$ & $F L$ \\
\hline 1 & 200 & 1415 & 0.3 & 10 \\
2 & 300 & 1415 & 0.3 & 10 \\
3 & 600 & 1415 & 0.3 & 10 \\
4 & 800 & 1415 & 0.3 & 10 \\
5 & 1000 & 1415 & 0.3 & 10 \\
6 & 1500 & 1415 & 0.3 & 10 \\
7 & 2000 & 1415 & 0.3 & 10 \\
8 & 2500 & 1415 & 0.3 & 10 \\
9 & 3000 & 1415 & 0.3 & 10 \\
10 & 460 & 1479 & 0.4 & 12 \\
11 & 1156 & 1479 & 0.4 & 12 \\
12 & 1900 & 1479 & 0.4 & 12 \\
13 & 225 & 513 & 0.3 & 10 \\
14 & 360 & 513 & 0.3 & 10 \\
15 & 250 & 511 & 0.4 & 10 \\
16 & 275 & 511 & 0.4 & 10 \\
17 & 305 & 511 & 0.4 & 10 \\
18 & 10 & 363 & 0.4 & 10 \\
19 & 24 & 363 & 0.4 & 10 \\
20 & 55 & 363 & 0.4 & 10 \\
21 & 200 & 363 & 0.4 & 10 \\
\hline
\end{tabular}


Table 4: Characteristics of wind turbines considered.

\begin{tabular}{ccc}
\hline Manufacturer & WT Power $(\mathrm{W})$ & WT Life (Year) \\
\hline 1 & 500 & 15 \\
2 & 1000 & 15 \\
3 & 5000 & 15 \\
4 & 10000 & 15 \\
5 & 15000 & 15 \\
6 & 20000 & 15 \\
\hline
\end{tabular}

Table 5: Optimization parameters and economic analysis.

\begin{tabular}{cc}
\hline Parameter & Assigned value \\
\hline Inflation rate (\%) & 3 \\
Discount rate (\%) & 5 \\
Project lifetime (years) & 40 \\
Maximum WTs & 1 \\
Maximum battery strings & 10 \\
Rated voltage (V) & 24 \\
Population size & 15 \\
Generations & 20 \\
Crossover rate (\%) & 90 \\
Mutation rate (\%) & 3 \\
EIU (\%) & 1 \\
\hline
\end{tabular}

Table 6: Evaluation of the configuration obtained by the proposed GA-based method.

\begin{tabular}{ccc}
\hline Parameter & GA method & Enumerative method \\
\hline WT manufacturer & $3(5000 \mathrm{~W})$ & $3(5000 \mathrm{~W})$ \\
Battery manufacturer & $11(1156 \mathrm{Ah})$ & $10(460 \mathrm{Ah})$ \\
Battery strings & 4 & 10 \\
Battery bank capacity $(\mathrm{kWh})$ & 110.976 & 110.4 \\
NPC & 213509.004547 & 203574.4 \\
EIU & 0.014231 & 0.00806 \\
Battery lifetime (year) & 4.193379 & 5.680022831 \\
Computational time (min) & 45.142167 & 161.659467 \\
\hline
\end{tabular}

Table 7: Stress factor and risk levels for optimal configuration.

\begin{tabular}{ccc}
\hline Stress factor & Value & Risk level \\
\hline$C F$ & $104.199255 \%$ & Low \\
$Q_{t h r}$ & 7.754557 & Very low \\
$I_{1 \%}^{\max }$ & 0.000503 & Very low \\
$T_{F}$ & 5.422348 days & High intensity \\
$T_{S}$ & $0.000000 \%$ & Very low \\
$P C$ & $31.074429 \%$ & Low \\
\hline
\end{tabular}

